\title{
Correction to: Religious Perfectionism Scale: Assessment of Validity and Reliability Among Undergraduate Students in Iran
}

\author{
Abbas Abdollahi ${ }^{1}$ (D) Zahra Azadfar $^{2} \cdot$ Christopher Boyle $^{3} \cdot$ Kelly-Ann Allen $^{4}$
}

Published online: 11 August 2021

○) Springer Science+Business Media, LLC, part of Springer Nature 2021

\section{Correction to: Journal of Religion and Health https://doi.org/10.1007/s10943-021-01362-y}

In this article, the affiliation details for first author "Abbas Abdollahi" were incorrectly given as "Department of Psychology, Faculty of Education and Psychology, Alzahra University, Tehran, Iran" but should have been "Department of Counseling, Faculty of Education and Psychology, Alzahra University, Tehran, Iran". This has been corrected with this erratum.

The original article has been corrected.

Publisher's Note Springer Nature remains neutral with regard to jurisdictional claims in published maps and institutional affiliations.

The original article can be found online at https://doi.org/10.1007/s10943-021-01362-y.

Abbas Abdollahi

a.abdollahi@alzahra.ac.ir

1 Department of Counseling, Faculty of Education and Psychology, Alzahra University, Tehran, Iran

2 Department of Psychology, Faculty of Education and Psychology, Alzahra University, Tehran, Iran

3 Graduate School of Education, University of Exeter, Exeter, UK

4 Educational Psychology and Inclusive Education, Faculty of Education, Monash University, Clayton, Australia 